\section{A CASE OF MALIGNANT DISEASE OF THE} PANCREAS.

Bx W. E. FOTHERGILL, M.A., B.Sc., M.B.Edin., Manchester; late House Physician (Gynæcological Department), Edinburgh Royal Infirmary.

THE following case of primary malignant disease of the pancreas presents some striking resemblances to the two described by Dr. Guthrie Rankin in the BrITISH MEDICAL JoURNAL of May 11 th, 1895 , and, like them, it differs from the classical descriptions of the condition.

On February 26th I saw, for Dr. Darling, of Edinburgh, Miss A., aged 53, a well nourished and healthy looking woman. She was dressed, sitting on a chair, and leaning over a basin. Between paroxysms of pain in the upper part of the abdomen she made ineffectual attempts to vomit. She had suffered from a similar attack in September, 1894, after which she had been somewhat jaundiced. The passage of gall stones was diagnosed. Great abdominal tenderness remained for the next few days, and there was threatened obstruction of the bowels, which was finally overcome by enemata. There was then some diarrhcea. The stools were all examined for gall stones, but none were seen; the motions were high coloured, and contained no fat.

The patient having become less fleshy, and the abdominal tenderness having disappeared, palpation now revealed a solid tumour in the epigastric and umbilical regions. It was surrounded by an area giving a clear percussion note, so being distinct from the liver, which was normal in size. There was no jaundice. The urine contained abundant sugar. Malignant disease affecting the pancreas was now diagnosed, but in the course of the week the patient had several violent rigors, which she attributed to chills on getting out of bed. She was on a milk diet, and there was now no disturbance of digestion. She slept very badly, and lost flesh rapidly. On March 12th a consultation was held, at which it was thought that the condition might be due to suppuration round an impacted gall stone, bearing in mind the history of gall stones in the previous September and the rigors. The surgeon who was asked to see her the same evening found her condition good enough to justify an incision in search of pus.

On March $13^{\text {th }}$ the incision was made, nothing being found but a firm tumour, consisting of infiltrated glands filling the centre of the abdominal cavity. That evening the patient began to vomit blood, and she died on the following day. The abdomen only could be examined post mortem. Its cavity contained very little fluid. The organs were considerably matted together, and the peritoneum was studded in parts with cancerous nodules. With some difficulty the mass of glands in the mesentery and omentum was unravelled, and the pancreas was found completely disorganised by malignant disease. The liver was not infiltrated.

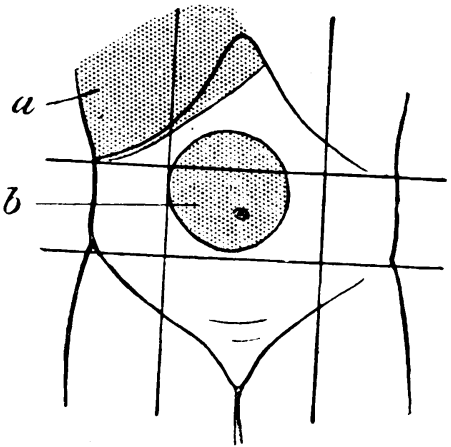

$a$, liver dulness; $b$, tumour dulness.

There were between 200 and 300 gall stones in the gall bladder, which was distended and had thickened walls, but showed no trace of malignancy or acute inflammation. No gall stone was impacted in any duct. The walls of the stomach were so thin and friable, as were those of the duodenum, that it was impossible to avoid tearing them. The vomited blood had apparently entered the stomach from a tear or ulceration near the pylorus. There was a fibroid tumour the size of a hen's egg attached to the fundus of the uterus by a pedicle. This fibroid was of stony hardness, being calcified throughout.

In this case, as in those reported by Dr. Guthrie Rankin, positive symptoms were rapid emaciation after an onset of paroxysmal pain, with deep-seated tenderness. As in his cases, there was absence of fatty stools and of marked digestive disturbance, of jaundice, and of a family history of malignancy. Here, however, glycosuria was a prominent feature of the case. The tumour, on palpation and percussion, was more in the umbilical than in the epigastric region. It gave the impression of being more firm centrally than superficially, which was so. Dr. Rankin's remarks appear to me to apply admirably to this case.

\section{A CASE OF SIMULTANEOUS UTERINE AND EXTRAUTERINE GESTATION.}

\author{
By THOMAS E. MITCHELL, M.B., B.C., \\ Old Hill, Staffs.
}

ON Christmas Day, 1894, I was called to see S. W., aged 30 , whose first child was little over a year old. She was of highly neurotic type, and had a strong family history of insanity. She was suffering from severe pain in the lower part of the abdomen, which came on suddenly. There was no collapse. Her last period had occurred on November 5 th, and she thought she might be pregnant. A vaginal examination revealed no symptoms of hæmatocele or other abnormality, except a slight tendency to prolapse of the bladder. Under rest and opiates the pain speedily subsided, and the patient went on well for some weeks, when she had an attack of influenza. She then complained of difficulty in micturition, but this was attributed to the condition of the bladder, and as she was a very neurotic subject no further vaginal examination was made at this time.

During March she again began to complain of abdominal pain, and the contour of the abdomen differed from that of normal pregnancy. To the right of, and nearly on the level with, the umbilicus, was a rounded globular swelling, clearly defined and resembling a gravid uterus. This was separated by a slight sulcus, from a diffuse, ill-defined swelling to the left of the umbilicus, over which could be heard a distinct souffle. No souffle could be heard at the right of the umbilicus, nor could the foetal heart at this, or any other time, be detected. The os uteri was tilted very much forward, and was so patulous that the finger impinged directly on the internal os. Behind, and to the left of the os, could be felt what was evidently a fotal head; the case was evidently not one of retroflexion, and I regarded it as one of extrauterine fœetation. Dr. Thompson, of Cradley, who saw the case in consultation, considered that there were strong grounds for this conclusion, but from the evidently enlarged condition of the uterus it was not considered advisable to introduce a sound or bougie into the uterus.

The patient was kept in bed, and opium was given for the relief of pain.

On April 27th pains resembling labour pains set in, and next day a bag of membranes presented, on rupturing which a hand, foot, and funis presented. The foot was brought down, and a fotus (5-6 months) was born. The placenta came away naturally, and there was no hæmorrhage. The swelling to the right now contracted to the usual cricket ball size, and that on the left became more central, and a blowing souffle could be heard over its surface.

On April 28th pains again commenced, and opium had to be pushed to its utmost limits to procure any cessation of the intense agony.

On the morning of April 29th, with the assistance of Dr. Griffith, of Netherton, who had occasionally seen the case with me, the patient was put under an anæsthetic, and a digital exploration of the uterus confirmed the view of extraaterine gestation. The chance of operation was offered, but not recommended, to the friends, as the pulse was now 120, and the facial aspect indicative of commencing peritonitis. Operative measures were declined, and the patient sank and died on the morning of April 3oth.

A very limited examination of the body was allowed. This 
showed the uterus firmly contracted. The fœtus, slightly smaller than its uterine fellow, lay in an adventitious sac behind the left broad ligament, to the posterior surface of which the placenta was attached. The peritoneum was full of blood-stained amniotic fluid, which escaped immediately the peritoneum was opened at the level of the umbilicus.

I think there is no doubt that an ante-mortem rupture resulting from the tugging of the uterine contractions had occurred. The position of the placenta anterior to the fœtus demonstrated the almost inevitable death from hæmorrhage, which must have preceded any delivery by laparotomy.

Although the souffle heard in pregnancy is held to be uterine and not placental, it was certainly heard in this case over the region of the placenta in an extrauterine sac. The accessible position of the fotal head in the pouch of Douglas suggests the possibility that in this case the fœtus might have been removed by the vagina.

I think the fœtation most probably was primarily tubal, and that the rupture of the tube occurred on Christmas Day, although the absence of collapse and symptoms of hæmatocele or peritonitis go far to negative this view.

\section{MEMORANDA: \\ MEDICAL, SURGICAL, OBSTETRICAL, THERA- PEUTICAL, PATHOLOGICAL, Etc.}

HYPERPYREXIA WITH COMA.

M. R., a female, aged 3 years, was out playing on May 13 th, a very hot day. In the evening, she complained of headache, and vomited several times. I saw her on May 14 th; she was then comatose; eyes deviated to the left; pupils fixed and contracted; carpopedal tonic contractions ; temperature $106^{\circ} \mathrm{F}$.

On the following day, the ocular deviation had disappeared; the pupils were contracted, fixed. Cheyne-Stokes respiration ; pulse rapid, irregular ; urine suppressed; skin hot and dry; temperature $107^{\circ} \mathrm{F}$. She died the same day, having been ill forty-eight hours. Half an hour after death, the rectal temperature was $105^{\circ}$.

The case presents the history and symptoms of hyperpyrexial insolation, a disease rare in this country, but common amongst children abroad. I am at a loss to what other cause to attribute the attack. The child had for a few days previously been "seedy" and out of sorts, an increased susceptibility to the sun's action being thus present; but she had presented no symptoms which might have pointed to meningitis. Cerebral hæmorrhage, to which some of the symptoms seemed to point, is so rare in healthy children that I think it may be dismissed as very improbable. Unfortunately, no post-mortem examination was allowed.

i Leicester. R. MilbouRne West, M.R.C.S., L.R.C.P.Lond.

Dr. MacGregor's case published on May i6th reminds me of one which occurred at sea. The child had had two convulsions the previous day, and was taken to see a medical man in Kingston, Jamaica, who said that she was teething. It embarked at 2 P.M., January Ioth, 1896, then being to all appearances in perfect health.

I was called at 4.30 P.M. and found a female child, aged I year, lying on her back, deeply comatose, the pupils semidilated, eyes wide open, the limbs cool and limp, the body hot and sweating, the head hot, and face pallid. The temperature was $108^{\circ}$. This was taken in both axillæ, and with four different thermometers. The respirations were 78 . The pulse very rapid, weak, and uncountable. There was no eruption and no diarrhœa. I gave hydrarg. subchlor. gr. iij on the back of the tongue, and applied ice to the head and chest. At 6 P.M. the temperature was $10 r^{\circ}$, respiration 54 , pulse I30. The bowels were opened. The temperature gradually rose again, and at 7.30 was $107^{\circ}$, the patient having slight general convulsions and stertorous breathing. She died at 8 P.M. No post-mortem examination was allowed.

Here, however, a suspicion of either malaria or sunstroke arises, as she came from Costa Rica, and the temperature at Kingston, where the family had stayed the week previous, was from $86^{\circ}$ to $89^{\circ}$.

Caversham Road, N.W.
NEURITIS OF THE PNEUMOGASTRICS.

IN the beginning of November, I893, J. H., aged 52, a man who had frequently been subject to attacks of gout, began to be sick after his meals, and to complain of gastric pain and discomfort after taking any kind of food. The sickness became frequent, and the flatulence and discomfort so marked and prolonged that he soon was unable to leave his bed. None of the ordinary remedies relieved him, and the most careful dieting had little effect in diminishing the sickness. There was extreme superficial tenderness over the epigastric region, but no tumour could be felt. He then began to have attacks of coughing, incessant, long continued, and most distressing. At intervals he had attacks of laryngeal spasm, which caused choking and much difficulty in inspiration. His heart action, which had throughout been rapid, became extremely so, and then he had attacks of heart failure, with a tendency to faintness, and the pulse became irregular, intermittent, and very feeble. On December 27 th heart failure and tendency to syncope were so marked that he constantly required subcutaneous injections of ether or inhalations of nitrite of amyl. The sickness had continued.

The case being then supposed to be hopeless, and probably one of malignant disease of the pylorus, all other treatment was given up, and he was kept well under the influence of opium, which up to that time had not been pushed but only used in small doses. The sickness ceased. By slow degrees he recovered his strength and was able to take food, and by the beginning of March was able to go out and resume his business. Two other cases presenting much the same symptoms had previously been noted in patients who frequently had gout. During the influenza epidemics of 1893,1894 , and 1895, other cases also markedly similar were observed by myself and Dr. Plummer. In some, the gastric symptoms predominated; in others, the laryngeal (not only laryngismus and extremely violent and prolonged fits of coughing were noticed-some had true expiratory asthma). In all, the heart's action was rapid, and there was tendency to faintness and prostration. Opium seemed to be the only efficacious remedy. Strychnine was injurious at any stage of the disease. In all cases there was prolonged illness and tendency to relapse. Restricting the amount of fluids to 30 or 40 ounces a-day seemed to relieve the gastric discomfort. ${ }^{1}$ Stimulants were used sparingly and carefully. From the various symptoms described, one may fairly infer that the lesion present was a neuritis of the pneumogastric, but whether of one or both nerves one cannot say. Marked tenderness on pressure was noted in some of the cases over the course of the nerve in the neck. West Bromwich.

\section{H. Langley Browne.}

DEFORMITY DUE TO PERIOSTITIS OF THE RIBS.

W. M., aged 16, a grocer's assistant, consulted me January, I 889 , about a protrusion of the left side of his chest, which occurred since a fall he had while playing football about four months previous to our interview. For two months he had been suffering from pain at the junction of the fourth rib with its cartilage, he describing it as sharp, shooting, and intermittent, not worse at any particular time in the twentyfour hours. About a month after the pain started he noticed a small prominence at the spot indicated, which slowly became more noticeable. With the appearance of the pain he noticed that his heart began to palpitate. His family history was good.

The patient was muscular, but rather anæmic; he stood with the left shoulder at a lower level than the right. There was no curvature of the spine. The left pectoral muscles were much atrophied, and there was a distinct bulging of the left side of the chest between the mammary and parasternal lines; the prominence was most marked at the junction of the fourth costal cartilage with the rib. The fourth, fifth, sixth, and seventh left ribs were much broader than those of the opposite side, and widely separated from each other over the convexity of the prominence, the space between the fifth and sixtl costo-chondral junction admitting two fingers. From this point they converged and almost touched one another in the mid-axillary line. The apex beat was appa-

1 A palatable and nutritious form of beef-tea can be made by adding a a teaspoonful of bovril to 6 ounces of lot milk. Flavour with celery salt. 